\title{
ASYMPTOTIC BEHAVIOUR OF SOLUTIONS OF NONLINEAR DELAY DIFFERENCE EQUATIONS IN BANACH SPACES
}

\author{
ANNA KISIOLEK AND IRENEUSZ KUBIACZYK
}

Received 1 June 2005

We consider the second-order nonlinear difference equations of the form $\Delta\left(r_{n-1} \Delta x_{n-1}\right)+$ $p_{n} f\left(x_{n-k}\right)=h_{n}$. We show that there exists a solution $\left(x_{n}\right)$, which possesses the asymptotic behaviour $\left\|x_{n}-a \sum_{j=0}^{n-1}\left(1 / r_{j}\right)+b\right\|=o(1), a, b \in \mathbb{R}$. In this paper, we extend the results of Agarwal (1992), Dawidowski et al. (2001), Drozdowicz and Popenda (1987), M. Migda (2001), and M. Migda and J. Migda (1988). We suppose that $f$ has values in Banach space and satisfies some conditions with respect to the measure of noncompactness and measure of weak noncompactness.

\section{Introduction}

Let $\mathbb{C}$ be the set of complex numbers and let $\mathbb{R}$ be the set of real numbers and $l_{1}(\mathbb{C})$ the space of complex-valued sequences $\left(c_{n}\right)$ such that

$$
\left\|\left(c_{n}\right)\right\|_{1}:=\sum_{i=1}^{\infty}\left|c_{n}\right|<\infty .
$$

Let $(X,\|\cdot\|)$ be a complex (real) Banach space and $l_{\infty}(X)$ denote the space of bounded sequences $x=\left(x_{n}\right)$ in $X$ with the norm

$$
\|x\|_{\infty}=\left\|\left(x_{n}\right)\right\|_{\infty}=\sup _{n}\left\|x_{n}\right\|
$$

With this norm $l_{\infty}(X)$ is a Banach space.

In this paper, we are concerned with the difference equation in Banach space:

$$
\Delta\left(r_{n-1} \Delta x_{n-1}\right)+p_{n} f\left(x_{n-k}\right)=h_{n}, \quad n \in \mathbb{N},
$$

where $\Delta$ is the forward difference operator, that is,

$$
\begin{aligned}
& \Delta x_{n}=x_{n+1}-x_{n}, \\
& \Delta^{2} x_{n}=\Delta\left(\Delta x_{n}\right),
\end{aligned}
$$

and $f: X \rightarrow X$. 
2770 Nonlinear delay difference equations in Banach spaces

By a solution of (1.3) we understand a sequence $x=\left(x_{n}\right)$ in $l_{\infty}(X)$ which satisfies (1.3).

The results obtained here generalize some results of M. Migda and J. Migda [9, 10]. In [10] the second-order difference equation of the form

$$
\Delta^{2} x_{n}=a_{n} \varphi\left(x_{n+k}\right), \quad n=1,2, \ldots, k=0,1,2, \ldots,
$$

was considered. Authors give a condition when this equation has a solution, asymptotically equal to $c, c \in \mathbb{R}$.

\section{Main results}

We give necessary and sufficient conditions for the existence of solutions.

Let $f$ be the function from $X$ to $X,\left(p_{n}\right),\left(r_{n}\right)$ sequences of real numbers, and $\left(h_{n}\right)$ a sequence in Banach space.

Let $D$ be a nonempty, closed, convex, and bounded subset of Banach space.

Our result will be proved by the following fixed point theorem.

Theorem 2.1 [5]. Let D be a nonempty, closed, convex, and bounded subset of Banach space.

Let $F: D \rightarrow D$ be a continuous mapping, which is condensing with respect to the measure of noncompactness $\alpha$ :

$$
\alpha(F(V)) \leq L \alpha(V), \quad L<1 .
$$

Then F has fixed point, where $\alpha$ is the Kuratowski's measure of noncompactness.

Theorem 2.2. Let $V \subset \mathbb{C}\left(N^{+}, X\right)$ be a family of functions. Then

$$
\alpha(V)=\alpha\left(V\left(N^{+}\right)\right)=\sup \left\{\alpha(V(i)): i \in N^{+}\right\},
$$

where $\alpha(V)$ denotes the measure of noncompactness in $\mathbb{C}\left(N^{+}, X\right)$.

A theorem similar to Theorem 2.1 was proved by Arino et al. [2], see also [8, 11], when $f$ is weakly-weakly sequentially continuous, that is, if $x_{n} \stackrel{w}{\rightarrow} x_{0}$, then $f\left(x_{n}\right) \stackrel{w}{\rightarrow} f\left(x_{0}\right)$ for each sequence $\left(x_{n}\right)$, and instead of $\alpha$ we used $\beta$-weak measure of noncompactness.

Theorem 2.3. Let $f: X \rightarrow X$ be the bounded and continuous function.

Let

$$
\begin{gathered}
t=\sum_{n=1}^{\infty}\left(\sum_{j=0}^{n-1} \frac{1}{r_{j}}\right)\left|p_{n}\right|<\infty, \\
\sum_{n=1}^{\infty}\left(\sum_{j=0}^{n-1} \frac{1}{r_{j}}\right)\left\|h_{n}\right\|<\infty .
\end{gathered}
$$

Moreover,

$$
\alpha(f(V)) \leq k \alpha(V)
$$

where $k t<1$. 
Then for every $a, b \in \mathbb{R}$ there exists a solution $\left(x_{n}\right)$ of (1.3) which possesses the asymptotic behaviour

$$
\left\|x_{n}-a \sum_{j=0}^{n-1} \frac{1}{r_{j}}+b\right\|=o(1) .
$$

Proof. Let $a, b \in X$. There exists a constant $M>1$ such that $\|f(t)\|<M$ for each $t \in X$.

Assume that

$$
\begin{gathered}
k_{n}=\left|p_{n}\right|+\left\|h_{n}\right\| \quad \text { for } n \in N, \\
l_{n}=\frac{1}{r_{n}} \sum_{j=n+1}^{\infty} k_{j} .
\end{gathered}
$$

From (2.3) we have

$$
\begin{aligned}
& \sum_{n=1}^{\infty}\left(\sum_{j=0}^{n-1} \frac{1}{r_{j}}\right)\left|p_{n}\right|+\sum_{n=1}^{\infty}\left(\sum_{j=0}^{n-1} \frac{1}{r_{j}}\right)\left\|h_{n}\right\| \\
& \quad=\sum_{n=1}^{\infty}\left(\sum_{j=0}^{n-1} \frac{1}{r_{j}}\right)\left(\left|p_{n}\right|+\| h_{n}||\right)=\sum_{n=1}^{\infty}\left(\sum_{j=0}^{n-1} \frac{1}{r_{j}}\right) k_{n} \\
& =k_{1} \cdot \frac{1}{r_{0}}+k_{2} \cdot\left(\frac{1}{r_{0}}+\frac{1}{r_{1}}\right)+k_{3} \cdot\left(\frac{1}{r_{0}}+\frac{1}{r_{1}}+\frac{1}{r_{2}}\right)+\cdots \\
& =\frac{1}{r_{0}}\left(k_{1}+k_{2}+k_{3}+\cdots\right)+\frac{1}{r_{1}}\left(k_{2}+k_{3}+\cdots\right)+\frac{1}{r_{2}}\left(k_{3}+\cdots\right) \\
& =\sum_{n=1}^{\infty} \frac{1}{r_{n-1}} \sum_{j=n}^{\infty} k_{j}=\sum_{n=1}^{\infty} l_{n-1} .
\end{aligned}
$$

So the series $\sum_{n=1}^{\infty} l_{n}$ is convergent.

Let $z_{n}=\sum_{j=n}^{\infty} l_{j}$ for $n \in N$.

Define the operator $T: D \rightarrow K$, where

$$
\begin{gathered}
D=\left\{y=\left(y_{1}, y_{2}, y_{3}, \ldots\right),\left\|y_{n}\right\| \leq M z_{n}\right\}, \quad n \in N, \\
K=\left\{y=\left(y_{1}, y_{2}, y_{3}, \ldots\right),\left\|y_{n}-\left(a \sum_{j=0}^{n-1} \frac{1}{r_{j}}+b\right)\right\| \leq M z_{n}\right\}, \quad n \in N .
\end{gathered}
$$

For $x \in D$ and $n \in N$ we have

$$
(T x)_{n}= \begin{cases}a \sum_{j=0}^{n-1} \frac{1}{r_{j}}+b, & n \leq m, \\ a \sum_{j=0}^{n-1} \frac{1}{r_{j}}+b-\sum_{j=n}^{\infty} \frac{1}{r_{j}} \sum_{i=j+1}^{\infty}\left(p_{i} f\left(x_{i-k}\right)-h_{i}\right), & n>m .\end{cases}
$$


2772 Nonlinear delay difference equations in Banach spaces

For $n>m$ we have

$$
\begin{aligned}
\left\|(T x)_{n}-\left(a \sum_{j=0}^{n-1} \frac{1}{r_{j}}+b\right)\right\| \\
=\left\|a \sum_{j=0}^{n-1} \frac{1}{r_{j}}+b-\sum_{j=n}^{\infty} \frac{1}{r_{j}} \sum_{i=j+1}^{\infty}\left(p_{i} f\left(x_{i-k}\right)-h_{i}\right)-a \sum_{j=0}^{n-1} \frac{1}{r_{j}}-b\right\| \\
=\left\|\sum_{j=n}^{\infty} \frac{1}{r_{j}} \sum_{i=j+1}^{\infty}\left(p_{i} f\left(x_{i-k}\right)-h_{i}\right)\right\| \\
\leq \sum_{j=n}^{\infty} \frac{1}{r_{j}} \sum_{i=j+1}^{\infty}\left\|p_{i} f\left(x_{i-k}\right)-h_{i}\right\| \leq \sum_{j=n}^{\infty} \frac{1}{r_{j}} \sum_{i=j+1}^{\infty}\left(\left\|p_{i} f\left(x_{i-k}\right)\right\|+\left\|h_{i}\right\|\right) \\
\leq \sum_{j=n}^{\infty} \frac{1}{r_{j}} \sum_{i=j+1}^{\infty}\left(\left\|h_{i}\right\|+M\left|p_{i}\right|\right) \leq \sum_{j=n}^{\infty} \frac{1}{r_{j}} \sum_{i=j+1}^{\infty} M k_{i} \leq M \sum_{j=n}^{\infty} l_{j}=M z_{n} .
\end{aligned}
$$

So the operator $T: D \rightarrow K$ and the continuity of $f, T$ is continuous.

Now, we will prove that $T$ satisfies condition (2.1) of Theorem 2.1.

Let $V \subset D$, where $V=\left\{v: v=\left(v_{1}, v_{2}, \ldots\right)\right\}$ and $T(V)=\{T(v): v \in V\}$.

Let $V_{k}=\left\{v_{k}: v \in V, v=\left(v_{1}, v_{2}, \ldots, v_{k}, \ldots\right)\right\}$. For $n \leq m$ we obtain

$$
\alpha(T(V))=\alpha\left(a \sum_{j=0}^{n-1} \frac{1}{r_{j}}+b\right)=0 .
$$

For $n>m$ we have

$$
\begin{aligned}
\alpha(T(V)) & =\sup _{n} \alpha\left(a \sum_{j=0}^{n-1} \frac{1}{r_{j}}+b-\sum_{j=n}^{\infty} \frac{1}{r_{j}} \sum_{i=j+1}^{\infty}\left(p_{i} f\left(V_{n}\right)-h_{i}\right)\right) \\
& \leq \sup _{n}\left[\alpha\left(a \sum_{j=0}^{n-1} \frac{1}{r_{j}}+b\right)+\alpha\left(\sum_{j=n}^{\infty} \frac{1}{r_{j}} \sum_{i=j+1}^{\infty}\left(p_{i} f\left(V_{n}\right)-h_{i}\right)\right)\right] \\
& \leq \sup _{n} \alpha\left(a \sum_{j=0}^{n-1} \frac{1}{r_{j}}+b\right)+\sup _{n} \alpha\left(\sum_{j=n}^{\infty} \frac{1}{r_{j}} \sum_{i=j+1}^{\infty}\left(p_{i} f\left(V_{n}\right)-h_{i}\right)\right) \\
& \leq \sup _{n} \alpha\left[\sum_{j=n}^{\infty} \frac{1}{r_{j}} \sum_{i=j+1}^{\infty} p_{i} f\left(V_{n}\right)+\sum_{j=n}^{\infty} \frac{1}{r_{j}} \sum_{i=j+1}^{\infty} h_{i}\right] \\
& \leq \sup _{n} \alpha\left[\sum_{j=n}^{\infty} \frac{1}{r_{j}} \sum_{i=j+1}^{\infty} p_{i} f\left(V_{n}\right)\right]+\sup _{n} \alpha\left[\sum_{j=n}^{\infty} \frac{1}{r_{j}} \sum_{i=j+1}^{\infty} h_{i}\right] \\
& \leq \sup _{n}\left(\sum_{j=n}^{\infty} \frac{1}{r_{j}} \sum_{i=j+1}^{\infty} \alpha\left(p_{i} f\left(V_{n}\right)\right)\right) \leq \sum_{j=n}^{\infty} \frac{1}{r_{j}} \sum_{i=j+1}^{\infty}\left|p_{i}\right| \alpha(f(V)) .
\end{aligned}
$$


Using the inequality

$$
\alpha(f(V)) \leq k \alpha(V)
$$

we obtain that

$$
\alpha(T(V)) \leq k \alpha(V) \sum_{j=n}^{\infty} \frac{1}{r_{j}} \sum_{i=j+1}^{\infty}\left|p_{i}\right| \leq k \alpha(V) .
$$

By Theorem 2.1 T has a fixed point, and by the definition of $T$ the solution $x=\left(x_{n}\right)$ satisfies the condition

$$
\left\|x_{n}-a \sum_{j=0}^{n-1} \frac{1}{r_{j}}+b\right\|=o(1) .
$$

This completes the proof of the theorem.

Because we can extend Theorem 2.1 as in $[2,8]$, so similar as Theorem 2.3 we can prove the following theorem.

Theorem 2.4. Let $f: X \rightarrow X$ be the bounded and weakly-weakly continuous function.

Let

$$
\begin{gathered}
t=\sum_{n=1}^{\infty} \sum_{j=0}^{n-1} \frac{1}{r_{j}}\left|p_{n}\right|<\infty, \\
\sum_{n=1}^{\infty} \sum_{j=0}^{n-1} \frac{1}{r_{j}}\left\|h_{n}\right\|<\infty,
\end{gathered}
$$

and $k t<1$.

Moreover

$$
\beta(f(V)) \leq k \beta(V) .
$$

Then for every $a, b \in \mathbb{R}$ there exists a solution $\left(x_{n}\right)$ of (1.3) which possesses the asymptotic behaviour

$$
\left\|x_{n}-a \sum_{j=0}^{n-1} \frac{1}{r_{j}}+b\right\|=o(1) .
$$

Remark 2.5. Observe that the class of continuous functions is different than the class of weakly-weakly sequentially continuous functions and weakly-weakly continuous functions.

There exist many important examples of mappings which are weakly sequentially continuous but not weakly continuous.

The relationship between strong weak and weak sequential continuity for mappings is studied in [3]. 


\section{Nonlinear delay difference equations in Banach spaces}

\section{References}

[1] R. P. Agarwal, Difference Equations and Inequalities. Theory, Methods, and Applications, Monographs and Textbooks in Pure and Applied Mathematics, vol. 155, Marcel Dekker, New York, 1992.

[2] O. Arino, S. Gautier, and J.-P. Penot, A fixed point theorem for sequentially continuous mappings with application to ordinary differential equations, Funkcial. Ekvac. 27 (1984), no. 3, 273279.

[3] J. M. Ball, Weak continuity properties of mappings and semigroups, Proc. Roy. Soc. Edinburgh Sect. A 72 (1975), no. 4, 275-280.

[4] J. Banaś and K. Goebel, Measures of Noncompactness in Banach Spaces, Lecture Notes in Pure and Applied Mathematics, vol. 60, Marcel Dekker, New York, 1980.

[5] G. Darbo, Punti uniti in trasformazioni a codominio non compatto, Rend. Sem. Mat. Univ. Padova 24 (1955), 84-92 (Italian).

[6] M. Dawidowski, I. Kubiaczyk, and J. Morchało, A discrete boundary value problem in Banach spaces, Glas. Mat. Ser. III 36(56) (2001), no. 2, 233-239.

[7] A. Drozdowicz and J. Popenda, Asymptotic behavior of the solutions of the second order difference equation, Proc. Amer. Math. Soc. 99 (1987), no. 1, 135-140.

[8] I. Kubiaczyk, On a fixed point theorem for weakly sequentially continuous mappings, Discuss. Math. Differential Incl. 15 (1995), no. 1, 15-20.

[9] M. Migda, Asymptotic behaviour of solutions of nonlinear delay difference equations, Fasc. Math. (2001), no. 31, 57-62.

[10] M. Migda and J. Migda, Asymptotic properties of the solutions of the second order difference equation, Arch. Math. (Brno) 34 (1998), no. 4, 467-476.

[11] A. R. Mitchell and C. Smith, An existence theorem for weak solutions of differential equations in Banach spaces, Nonlinear Equations in Abstract Spaces (Proc. Internat. Sympos., Univ. Texas, Arlington, Tex., 1977) (V. Lakshmikantham, ed.), Academic Press, New York, 1978, pp. 387-403.

Anna Kisiolek: Institute of Mathematics, Poznan University of Technology, 5 Maria SklodowskaCurie Square, 60-965 Poznan, Poland

E-mail address: akisiolek@fabryka.net.pl

Ireneusz Kubiaczyk: Collegium Mathematicum, Adam Mickiewicz University, Umultowska 87, 61 614 Poznan, Poland

E-mail address: kuba@amu.edu.pl 


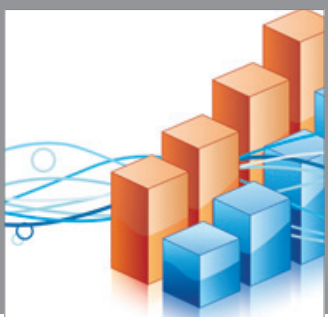

Advances in

Operations Research

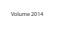

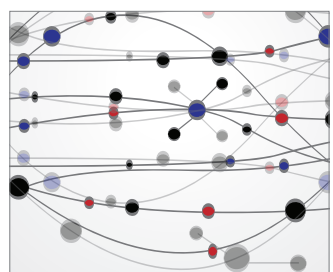

\section{The Scientific} World Journal
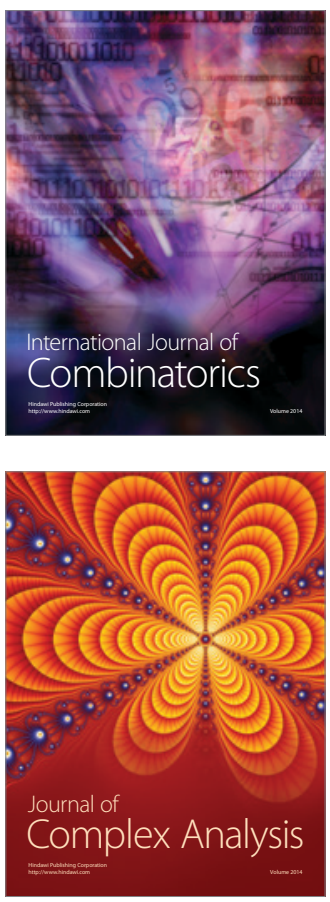

International Journal of

Mathematics and

Mathematical

Sciences
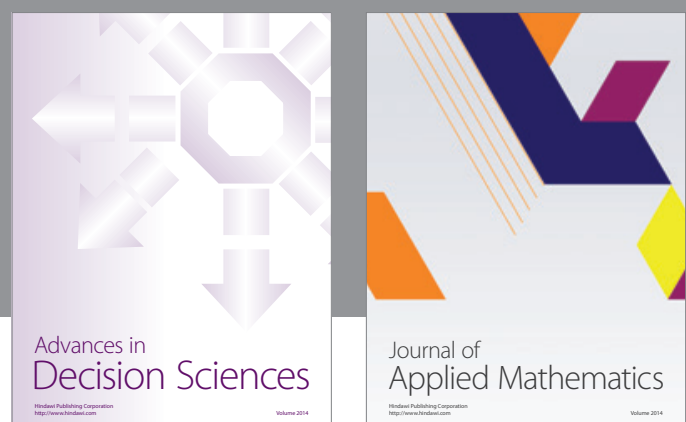

Journal of

Applied Mathematics
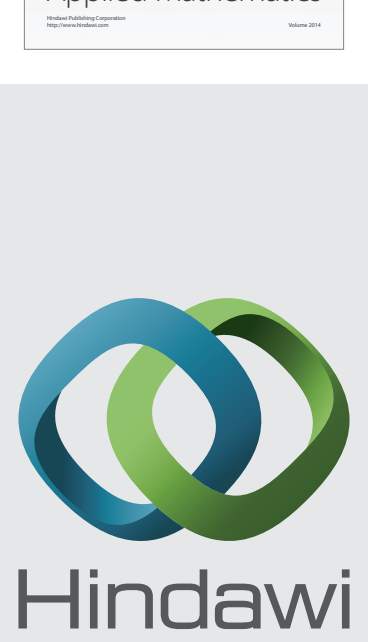

Submit your manuscripts at http://www.hindawi.com
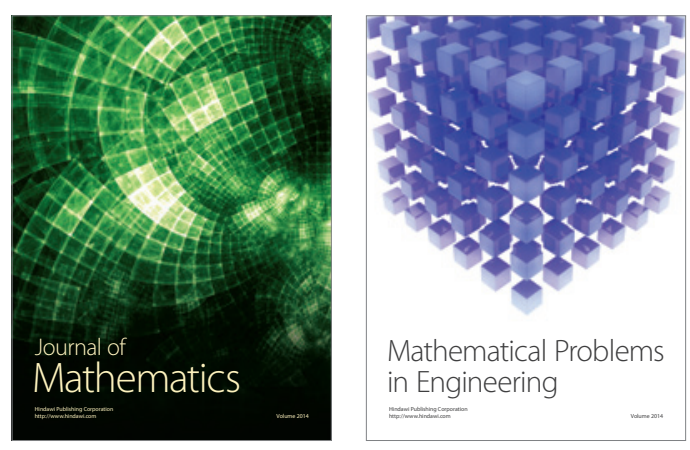

Mathematical Problems in Engineering
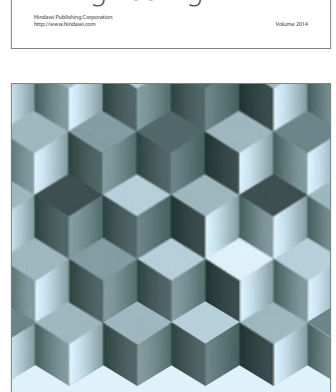

Journal of

Function Spaces
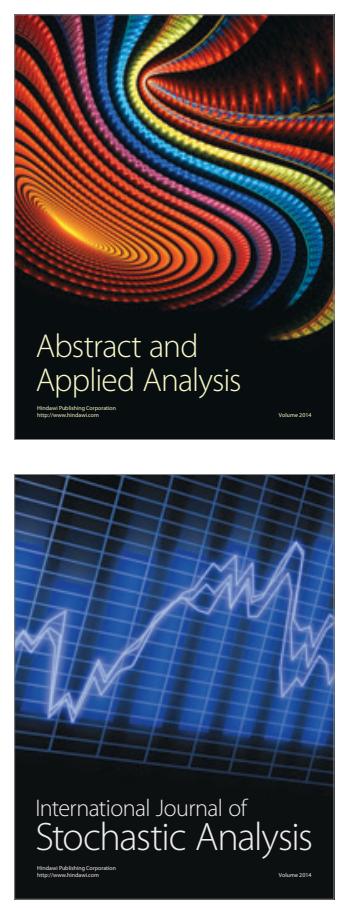

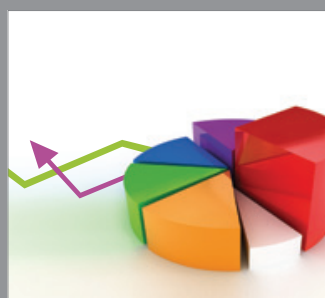

ournal of

Probability and Statistics

Promensencen
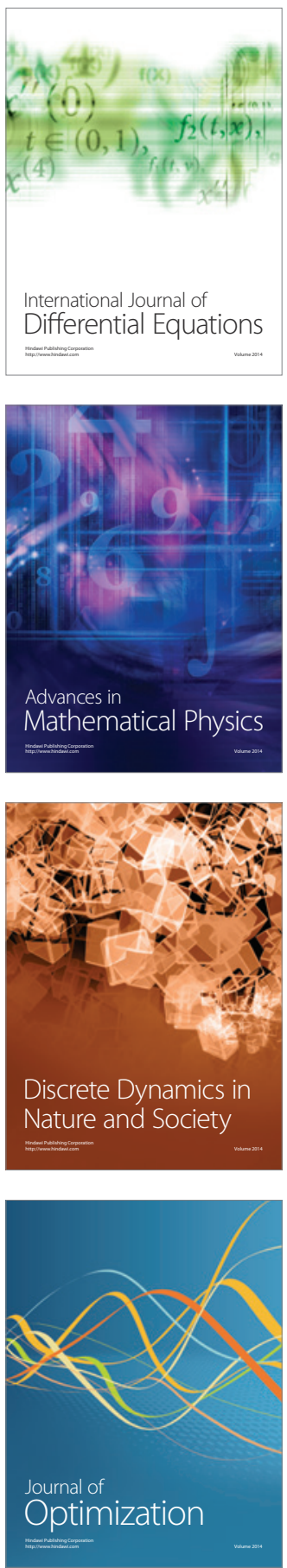